exist in liquid dinitrogen pentoxide. It is not possible, however, with the higher oxide, to invoke the aid of visually discernible electrolytic effects. But a strikingly significant reaction occurs when small pieces of clean soditum are added at $-40^{\circ}$ to liquid dinitrogen pentoxide (obtained as a straw-coloured liquid by melting almost colourless crystals of the oxide). The reaction takes place with very great vigour-much more vigorously than the corresponding reaction with liquid dinitrogen tetroxide; there is copious evolution of brown fumes of nitrogen dioxide and a white crystalline solid remains, which on isolation has been identified as sodium nitrate by ordinary analytical and by crystallographic tests. For sodium nitrate to be formed under these conditions, it is necessary to postulate the existence or the prior formation of nitrate ions in the pentoxide. This, it is submitted, could result from the polarized $\delta+\delta-$

$\stackrel{\mathrm{NO}_{2}}{-}-\stackrel{\delta}{\mathrm{NO}}{ }_{3}$ molecule becoming ionized to $\mathrm{NO}_{2}^{+}$and $\mathrm{NO}_{3}-$ under the agency of the sodium. It cannot, however, be affirmed unequivocally what the state of the molecule in liquid dinitrogen pentoxide is until further work along a variety of lines has been undertaken. Nevertheless, the observation does give strong confirmation to the deductions from cryoscopic and Raman spectral measurements.

Detailed discussion of the significance of these observations will be given later elsewhere.

${ }^{1}$ Addison, C. C., and Thompson, R., Nature, 162, 369 (1948).

${ }^{2}$ Angus, W. R., and Leckie, A. H., Trans. Farad. Soc., 31, 958 (1935). ${ }^{3}$ Gillespie, R. J., and Millen, D. J., Quart. Rev., 2, 277 (1948).

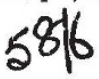

\section{REFINING OF NON-FERROUS METALS}

A SYMPOSIUM on the refining of non-ferrous metals, orgafiged by the Institution of Mining and Metalluy pto place on July 7-8, 1949, at the Institution Mechanical Engineers, Storey's Gate, London. The programme of nineteen papers ranged overfall blaisses of metals - base, precious, light, semirare ${ }^{\text {nd }}$ rare-tand was arranged in four sessions at which the foairmen were Mr. W. A. C. Newman (president of the Institution), Sir Arthur Smout, Sir Paul Gueterbock and Prof. C. W. Dannatt. In the following brief summary of the proceedings the papers are, for convenience, grouped somewhat differently from the sessional order.

Three papers were devoted to copper. H. J. Miller discussed very fully the development of fire refining, giving the details of the process and the reactions involved, the paper being made the more complete by treatment not only of the removal of impurities, but also of the influence of impurities on the properties of copper and of the casting of refined copper products. While mainly concerned with the reverberatory furnace process, the use of rotary furnaces was described and illustrated, and reference was made to direct arc and induction furnace methods in use in North America. R. H. Bauld's paper on melting and casting of high-conductivity wire bars was particularly interesting, because it discussed the attempts made to depart from the traditional method of reverberatory furnace refining followed by casting on wheels with horizontal moulds open to the atmosphere. Mr. Bauld only mentioned this method briefly, and then went on to discuss the production of oxygen-free high-conductivity copper at Carteret and the direct furnace melting of cathodes as pioneered by the Ontario Refining Co. The casting of vertical instead of horizontal bars was dealt with, and the final section of the paper was concerned with continuous casting, both by the Welblund-Benard machine at Carteret and the new installation, by the United States Metals Refining Co., of a JunghansRossi machine for casting round or rectangular sections. This description was particularly valuable because it dealt with a process the products of which are only just coming on to the market. The third of the papers on copper (by W. J. Friggens, E. W. Page and T. Milligan) described in detail the new electrolytic copper refinery at Nkana. This is on traditional and somewhat conservative lines.

Providing as they did factual information on the processes carried out and plant used, the copper papers did not lend themselves well to discussion; but an immense amount of useful data was compressed into these three contributions, which between them give a good up-to-date picture of the refining and casting of copper.

The paper on lead refining at Port Pirie, South Australia, by Mr. F. A. Green, dealt with what was described by Sir Paul Gueterbock (the chairman) as one of the most remarkable metallurgical processes in the world. In this, the Williams continuous leadrefining process, base lead bullion is treated for successive removal of copper (by drossing and sulphur treatment), arsenic and antimony (by oxida. tion), silver (by zinc), and finally removal of the zine used in desilvering. In the lively discussion which followed, one speaker wondered whether the liquid layer parts of the method had been influenced by the Harris process of lead refining, which perhaps had not received the general appreciation it deserved. Others drew an analogy between the oxidation of the arsenic and antimony in the softening process, and certain oxidation phenomena in steel production. Mr. S. B. Haney (who presented the paper on lead on behalf of the author) indicated in answer to various comments that the price of chlorine is a barrier to its use for the removal of zine remaining after desilverization; nevertheless the idea is being kept in mind. He also disclosed that latterly his company had been investigating the removal of zine from lead by vacuum distillation, as developed by Isbell of the St. Joseph Lead Co. This interesting process is being applied by the Company to 100 -ton batches of lead; by the American Smelting and Refining Co. in 200-ton kettles with 180 tons intake; while at Port Pirie 100-ton batches of desilverized lead with 0.56 per cent of zinc are being treated.

At the same session as the paper on lead, zinc and tin were discussed. Mr. Stanley Robson's paper on zinc refining was a concise account of the various stages in the development of zinc metallurgy. Horizontal retort distillation was the original method. Some purification is effected by liquation of the product (this permits of reduction of the lead content to 1 per cent). Another method of increasing the purity is insertion of a filter-plug between retort and condenser, this idea being further tried in the redistillation of zinc metal. Finally, Peirce and his associates of New Jersey have developed fractional distillation of zinc in vertical retorts. This latter method brilliantly solves the problem of purification by distillation, giving a zinc of 99.996 per cent purity (less than 0.001 per cent lead and 0.002 per cent iron), using units treating 50-60 tons per day. Brief reference was made to electrolytic zinc refining. $\mathrm{Mr}$. 
E. $H$. Jones's paper on tin reviewed the properties of the metal and its compounds which determine the refining methods used, and described at some length the principles and operation of a large number of available processes. He emphasized that the particular combination of methods used at any one refining plant is chosen largely on grounds of flexibility, since batches of ore and secondary metal of widely varying composition might be handled.

Of the two contributions on precious metals, that by Mr. A. E. Richards was a wide survey of methods of refining gold and silver. In his introductory remarks he stressed the importance of correct sampling of refinable bullion, particularly if the bullion is of comparatively low grade; as well as the necessity for speed in refining, owing to the value of the material, which might be subject to market fluctuations. This factor of value also bears on the choice of the refining process. Mr. H. Gordon Dale's paper was, on the other hand, concerned with the recovery of precious metals in general from residues and wastes in the industry. He likewise underlined the importance of correct assaying and sampling, particularly in the case of 'sweeps', which are often of a complex and varied nature. In the discussion of these papers, reference was made to the virtual extinction of the 'Wohlwill' gold-refining process, and to the present use of chlorine for refining the bulk of the gold in the world. The latter, however, yields a product which is troublesome in mechanical treatment, so that most gold used by jewellers is chlorinerefined material which has been re-refined. $\mathbf{M r}$. Richards agreed that the use of the chlorine process on a larger scale is a future possibility.

The light metals were the subject of three papers. Mr. E. F. Emley, introducing his paper on magnesium refining, mentioned that the preparation of satisfactory castings and other products free from non. metallic inclusions of oxide and flux residues has necessitated the development of special flux treatments to clean the molten metal. The action of these cleaning fluxes has been thoroughly investigated. The true refining processes in which, by flux action or by precipitation, metallic impurities are removed from magnesium, have been less completely investi. gated, and fundamental thermodynamic data applicable to the flux-refining process are lacking. In the discussion, Dr. P. Gross expressed surprise that the refining of magnesium by vacuum distillation, a less difficult operation than might be supposed, has not received wider application.

The electronegative character of aluminium, and special difficulties associated with direct distillation processes, are the reasons why present commercial refining methods for this metal depend on the electrolysis of a fused salt mixture. Such processes require large amounts of electrical energy and are therefore expensive. In bringing forward his paper on aluminium refining, Mr. J. Waddington remarked that the development of a satisfactory physical refining process for aluminium would completely change the aluminium industry. Not only would it facilitate the refining of scrap metal, but also the existence of such a process would enable impure metal from the reduction of unpurified bauxite to be brought to normal standards of commercial purity. The "Catalytic Distillation of Aluminium", by Dr. P. Gross, the third paper of the group, described a physical refining process in course of development. Under suitable conditions, aluminium trichloride can be made to react with molten aluminium to form unstable aluminium monochloride, this reverting on cooling to trichloride vapour and metallic aluminium which condenses. Volatile impurities, zine or magnesium, will distil with the aluminium, and have first to be removed by vacuum heating. Iron and silicon, however, have negligible vapour pressures at the temperatures at which catalytic distillation of aluminium is possible.

The group of materials comprising ferro-alloys, chromium, manganese, etc., was covered in two papers. In dealing with "The Alumino-Thermic Process", Mr. T. Burchell, after a general description, discussed in detail the preparation of commercially pure chromium, manganese and ferro-columbium. He mentioned the lack of adequate data on the thermochemical considerations governing these reactions, which actually occur in solid, liquid and gaseous phases. In the subsequent discussion the opinion was put forward that lower oxides of aluminium, such as the suboxide $\mathrm{Al}_{2} \mathrm{O}$, may play a more important part in the reaction than had been thought. For example, the attack of aluminium vapour on alumina films on aluminium particles to give a volatile suboxide may explain the great acceleration of these reactions. Mr. Burchell, however, considered that the reaction is more likely to be accelerated by decomposition of oxides by heat. Mr. J. A. Blake, presenting a paper on "Low-carbon Ferro Chrome", described the production of material to meet requirements of a ferro-alloy for the production of stainless steel. The process is designed to eliminate carbon by making use of the greater affinity of chromium for silicon. It is worked in two stages, and in reply to a suggestion that theoretically it should be possible to work a one-stage process, the author said that in practice this had not been found feasible.

Of the remaining papers, two were by Mr. A. R. Powell. In "Problems in the Production of Some of the Rarer Metals", he touched briefly on gallium, germanium, indium, thallium, rhenium and various others. He pointed out in his introductory remarks that the properties of some of these metals in the purest state are not known, owing to the difficulties presented in their production. The removal of metallic impurities is comparatively simple; but the metals easily form oxides, hydrides or nitrides, the presence of which has a considerable effect on properties. In reply to the discussion the author said that a suitable refractory for use in refining is thoria, which, however, is expensive : there are possibilities in lime or baryta crucibles. Mr. Powell's second paper dealt with the refining of bismuth, by essentially metallurgical methods, including its recovery from copper and lead, treatment of the rich bismuth lead alloy, desilverization, and removal of zinc and lead, with finally a brief account of the equipment and operation of a small refinery.

"Tungsten : its Preparation and Use in Electronics and Carbide Products" was presented by Mr. F. Smeaton, who covered production by ordinary wet methods from ore and scrap. There was some discussion of the mechanism of the reduction of tungstic oxide by hydrogen and of the part played by water vapour in the reaction. Mr. P. S. Bryant described the production of cobalt (by a wet chemical method culminating in reduction of the oxide by hydrogen), using as raw material a granulated alloy of cobalt, copper and iron arising from the treatment of converter slags from a Rhodesian copper refinery.

Dr. G. L. Miller dealt with the production of ductile zirconium, including the van Arkel iodide method of 
purifying the crude metal and the Kroll process, consisting of preparation of the chloride and its reduction by magnesium. He looked forward to elimination of the intermediate production of crude metal in the iodide process, and to a continuous iodide process with a travelling filament. In the discussion mention was made of the possibility of thermal reduction of zirconium chloride with hydrogen, a method which has been used in Germany for titanium.

Finally, it remains to mention a paper on spectrographic control in metal refining, in which Mr. D. M. Smith outlined factors affecting choice of technique and detail of method. Mention was made of the complementary nature of chemical and spectrographic methods of analysis, and this aspect also received attention in the discussion.

Over such a wide field (in some of which relatively few people are experienced) the amount of discussion was naturally variable, but those who attended had an opportunity, which can only rarely be repeated, of hearing about the refining of a large variety of metals from the actual practitioners. It is to be hoped that the complete record of the proceedings will be published as soon as possible, for it will form an authorita. tive account of modern practice in a most important branch of industry.

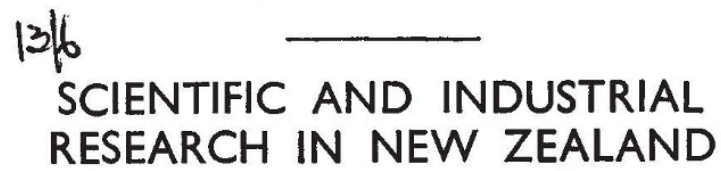

$\mathrm{T}$ HE twenty-second annual report of the Department of Scientific and Industrial Research, New Zealand, covering the year 1947-48, is much less detailed than preyious reports, although the activities of the Deputtanent have expanded during the year, to meet. marked increase in the immediate demarforfor scientific assistance from State depart. monts and industry and in an attempt to anticipate this-scientific needs of the next decade. Both the accompanying Minister's Statement and the Secretary's report refer to difficulties experienced through the limited number of qualified scientific workers, as well as through lack of suitable accommodation. Nevertheless, arrangements have been made for officers to take courses of studies in overseas institutions and to attend scientific conferences abroad. Increased collaboration between various branches of the Department and with other State departments has diminished the handicaps of shortage of staff and accommodation. Besides the formation of a Hop Research Association, a Leather and Footwear Research Association, which will extend the scope of the existing Leather Research Association, was formed during the year.

Regional soil surveys have been completed over extensive areas in South Island, and more extensive surveys undertaken for special purposes in North Island. Pasture research has been extended to hillcountry areas and intensified on flat country, while progress is reported in pasture-management research and in the understanding of the nutrition requirements of ordinary pastures. The new wheat variety, "Hilgendorf" has provided the Dominion with a grain of exceptionally high protein quality with no loss of yield. A comprehensive study of frost damage has been inaugurated in fruit and horticultural crop areas, while soil and manurial investigations are assisting in the extension of the tobacco crop and improving its yield. Chemical studies of tobacco leaf correlated with quality tests are throwing much light on the smoking quality of New Zealand-grown tobacco; much useful new knowledge has also been gained on the propagation and management of the native fibre plant Phormium, the source of New Zealand flax.

Arrangements have almost been completed for establishing, under Canterbury University College, an Industrial Development Department which will provide service, development and research for South Island manufacturers. Extensive geophysical surveys have been carried out for the State Hydro-electric Department in connexion with foundation studies for the construction of dams on the Waikato River. A feature of the work of the soil physics section of the Soil Bureau has been investigations of foundations for large buildings, factories, mills, earth dams and tanks. The fruit research activities of the Department have been reorganised and consolidated into a branch under a director, and special attention has been given to research problems affecting building and civil engineering.

An investigation on anomalous radar propagation carried out jointly by the United Kingdom and New Zealand Governments at Ashburton concluded its field work. The Plant Chemistry Laboratory and the Dominion Laboratory have installed a plant for the preparation of antibiotic substances and small amounts of penicillin have been made. Further points from the reports of the research committees which may be mentioned include the establishment of an Aeronautical Research Committee; the recommendation, as a result of biological tests on their toxicity against insects by the Plant Diseases Division, of six chemicals and proprietary mixtures for use as timber preservatives; further work on the refrigerated gas storage of apples; and trials of D.D.T. sprays both for their effect on the cold-storage quality of apples and for control of codling moth.

The Industrial Psychology Division commenced a survey of the present trend towards decentralization in New Zealand industry and investigated the use of psychological techniques for selecting personnel in some of the skilled ground-staff grades of the Royal New Zealand Air Force. At the Cawthron Institute, studies on tomato soils and on the incidence of 'cloud' in Nelson tomato-houses continued, while at Canterbury Agricultural College the fungus responsible for prevalent foliage disease of field and garden peas was isolated and studied. In the Agronomy Division, 'Agroxone' has replaced 'Sinox' for routine spraying of nucleus-seed crops of linen flax and linseed for control of weeds.

\section{SCIENCE MASTERS' ASSOCIATION}

\section{SUMMER MEETING}

$\mathrm{B}$ $Y$ kind permission of the Admiralty and of RearAdmir b W. Faulkner, and on the invitation of the holy Master and staff, the Science Masters' Associat" held a summer course on "Science and Sea froblems" at the Royal Naval College, Dartmoutbldurirld the first week of August. The course chasisted of ledtures by some of the leading members of the Rog I Naval Scientific Service and of displays of experinfental work both by members of the College and by the general members of the Association. In addition, visits were paid to the Royal Naval 